\title{
The Beneficiary Pays Principle and Luck Egalitarianism
}

Robert Huseby,

Department of Political Science,

University of Oslo

roberthu@stv.uio.no

Bio: Robert Huseby is a Professor of Political Science at the University of Oslo. His research interests include distributive justice and climate ethics. His work has been published in journals such as Environmental Ethics, Journal of Applied Philosophy, Journal of Political Philosophy, Politics, Philosophy \& Economics, and Utilitas.

\begin{abstract}
:
According to the Beneficiary Pays Principle an agent who, even innocently, benefits from an injustice may have a special duty to compensate the victim of that injustice. According to Luck Egalitarianism, it is unjust if someone is worse off than others, through no fault or choice of her own. These two principles differ widely, both in extension and justification, but tend nevertheless to yield similar conclusions in many cases. One reason is that, typically, the beneficiary and the victim of an injustice become better and worse off through no fault or choice of their own. This paper outlines some of the relevant differences between the two principles, and asks which of the two is intuitively more plausible. The conclusion is that Luck Egalitarianism is clearly more plausible than the Beneficiary Pays Principle. In light of this, the paper examines some further theoretical defenses of the Beneficiary Pays Principle, and finds them unsuccessful.
\end{abstract}




\section{The Beneficiary Pays Principle and Luck Egalitarianism}

\section{Introduction}

According to the Beneficiary Pays Principle (BPP) an agent who, even innocently, benefits from an injustice may gain a special duty to compensate the victim of that injustice, at least if other agents with stronger duties are not available. According to Luck Egalitarianism (LE), it is unjust if someone is worse off than others, through no fault or choice of her own. These two principles differ widely with regards to both extension and justification, but tend nevertheless to yield similar conclusions in many (hypothetical and isolated) cases. One reason is that, typically, the innocent beneficiary and the victim of an injustice become better and worse off, respectively, through no fault or choice of their own. Whether they also become better and worse off than others depends on the further details of the case, though these details are usually not provided in discussions of BPP. The tendency these principles have to yield overlapping implications in theoretical examples makes it interesting to ask which is more plausible. I will, through a series of cases tracking the structural difference between the two principles, argue that LE is clearly more plausible than BPP.

Additionally I offer a critique of some important theoretical defenses of BPP. The reason is that even if BPP is intuitively less plausible than LE, it is still worth assessing the theoretical 
underpinnings of the principle, as these may bring to light features that are not as apparent in single cases. I conclude, however, that these defenses do not give us reason to affirm the BPP.

It is worth noting that Carl Knight has recently explored some of the issues with which the present paper is concerned. ${ }^{1}$ Specifically, he too argues that LE is more plausible than BPP. The main positive contribution of this paper consists in furthering the debate by providing a more systematic and comprehensive comparison of the two principles. Whereas Knight singles out one kind of case in which LE and BPP yield different conclusions, I discuss four types of cases, each one tracking an important structural difference between the two principles. I show that LE is preferable in all these scenarios. Hence, this paper provides a much firmer ground on which to comparatively assess LE and BPP than has previously been available.

\section{BPP and LE}

BPP pertains to cases involving three parties: a perpetrator, a victim, and an innocent beneficiary. A simple case is one in which Peter innocently benefits from the harm that Paul inflicts on Mary. The details can vary, but this type of relation can be found in many situations. Consider climate change. Many people in the rich industrialized parts of the world now benefit from their ancestors' pollution, while many people in poorer parts of the world, are (or will be) harmed by the same pollution. The current rich, however, are arguably innocent with regard to their forbears' actions. I use the example of climate change because BPP has been extensively discussed in this context. ${ }^{2}$ It could be the case, however, that the harms caused by our forebears do not count as injustices as such, perhaps because they were unaware of the harmful effects of their actions. If so, one could interpret BPP such that it covers cases of innocently benefiting from harm (unjust or not). Also in cases of historical injustice it could be argued that descendants of colonialists now benefit from earlier 
generations' misdeeds, while others are still severely disadvantaged by them. ${ }^{3}$ Again, the descendants of the colonialists are (at least partly) innocent.

According to BPP, Peter, as well as the descendants of polluters and colonialists may have special duties to compensate the victims of the injustices that they have innocently benefited from, because they have benefited from injustice. BPP can be formulated like this:

If an agent $\mathrm{A}$ benefits from an unjust ${ }^{4}$ action $\mathrm{x}$ that she did not perform, and an agent $\mathrm{B}$ is harmed by $\mathrm{x}$, then, if $\mathrm{B}$ did not perform $\mathrm{x}$, A (may) in virtue of benefiting from $\mathrm{x}$, owe(s) B compensation (which is not to exceed A's gain from $\mathrm{x}$ ), insofar as no other agent has stronger duties to compensate B. ${ }^{5}$

'Actions' refer to all instances of human agency, not only those for which the agent can be held morally responsible (though I will be most interested in those). The relevant contrast is thus events, which are not caused by human agency. (There are of course many mixed cases, but here this intuitive distinction will suffice).

BPP may be formulated in stronger or weaker terms. I take it that most versions would hold that duties arise on the part of $\mathrm{A}$ if the conditions specified in the definition hold, but there could be versions which merely state that duties may arise on the part of A if the conditions hold. In the following, I will restrict my attention to the first kind. The reason is that it is hard to evaluate principles that may (or may not) be activated in circumstances $\mathrm{x}, \mathrm{y}$, and z. (I am not thereby indicating that such principles are implausible.) Several authors have recently defended or accepted (some version of) BPP. ${ }^{6}$ Others, however, are less enthusiastic. ${ }^{7}$

According to LE, agents ought morally to have equal levels of welfare (or resources, or capabilities) unless inequalities are due to the agent's own choices. In Larry Temkin's words "... it is bad - unjust and unfair - for some to be worse off than others through no fault [or choice] of their own." ${ }^{8}$ G. A. Cohen expresses a similar view when he claims that "...luck 
egalitarians accounts it an unfairness when some are better off than others through no fault or choice of their own." According to Arneson, "...[o]ther things equal, it is bad if some people are worse off than others through no voluntary choice or fault of their own." ${ }^{10}$ While it is not always explicitly stated, LE usually also holds that it is unjust if people are equally well off if they have displayed unequal levels of responsibility. ${ }^{11}$

There is a lively debate about the proper currency of justice. Here I will for simplicity assume that welfare is what luck egalitarians should aim to equalize. One practical reason for this is that benefits as understood by BPP-defenders, clearly encompasses more than mere resources. $^{12}$

The most striking similarity between BPP and LE is that both principles mandate that, in some circumstances, those who are, through no fault or choice of their own, deprived, should be compensated by those who, through no fault or choice of their own, have gained. Two hypothetical examples that have been introduced in order to support the plausibility of BPP illustrate this similarity well. Daniel Butt has an inventive story which involves four people, A, B, C, and D, living together (but having little interaction) on a remote island.

... The only crop which will grow on the island is the extremely versatile Polychrestos plant ... $[T]$ he island's underground river distributes water evenly throughout the island's soil... In order for each person to support herself, she must produce 200 kilos of root per year. A is a very hardworking, industrious type, whose agricultural efforts ... mean that she produces 700 kilos per annum ... B, C, and D are rather laid-back in their approach to agriculture, and works just five hours a day to produce the minimum 200 kilos a year ... D, a rather unsavoury character, decides she does not want to work even five hours each day. Unknown to all the others, she diverts the underground river away from B and C's sections of the land, so that her land receives all of their water ... When harvest time comes, ... A harvests her regulation 700 kilos. C's land has had no water, and consequently she has no crop ... It also emerges that D (no water 
engineer) has in fact diverted the water away from her own land as well as that of $\mathrm{C}$, and $\mathrm{B} \ldots$ has been a beneficiary. To her surprise, she harvests 400 kilos. D... hangs herself with a rope fashioned from the last year's Polychrestos crop. This leaves the problem of C. Without her year's produce, $\mathrm{C}$ will die unless A and B provide her with the necessary 200 kilos. How should the remedial responsibilities be distributed $?^{13}$

A further case is provided by Robert Goodin and Christian Barry.

...suppose your father had bribed a Harvard official to secure your admission to study there. Further suppose that it is certain that you would not otherwise have been admitted. Finally, suppose your life has gone very much better than it would otherwise have done in consequence.

But suppose, at age 50, you discover incontrovertible evidence of your father's misdeed: clearing up his estate, you find all the correspondence, along with the cancelled cheque. You learn from the Harvard archives who was next candidate for admission on the waitlist for your year. Tracking him down, you discover he was distraught at not getting into Harvard, became an auto mechanic instead, had been in and out of gaol, and led a pretty unhappy life quite generally in consequence of not being admitted to Harvard. ${ }^{14}$

In these cases - cases that are designed to lend intuitive support to BPP - LE implies the exact same conclusion as BPP, namely that the beneficiaries of injustice should compensate the victims of injustice. To be sure, in the Harvard case, we have to suppose that the beneficiary and the victim are initially justly equally well off (or at least that the victim is not unjustly better off than the beneficiary), before the injustice occurs, and we have to further assume background conditions of just equality. Apart from that, LE and BPP converge.

This is also true of the Polychrestos-case. Here we know that there is unjust inequality (in light of LE), that calls for transfers from beneficiary to victim, assuming that the islanders are the only agents available. A has what she is entitled to. Her yield is a consequence of her own 
efforts. B and C, on the other hand, have more and less, respectively, than they are entitled to in light of their display of responsibility. Thus, LE and BPP both demand transfers from B to C. All this, again, is not to suggest that the two principles overlap generally, only that they tend to yield the same conclusion in isolated cases.

\section{Comparative Plausibility}

In order to consider the (comparative) plausibility of the two principles (my purpose in this section is not to assess either principle as such), I will organize my discussion in line with four structural differences between LE and BPP that seem particularly relevant. I will present a series of stylized cases that are designed to isolate one structural difference at the time. In all these cases (unlike most of the standard cases in the literature) BPP and LE yield different conclusions. As it turns out, LE is consistently more plausible than BPP. Therefore I will in the next section consider some further theoretical defenses of BPP.

\subsection{Differences}

First, BPP pertains (in most versions) only to benefits and losses that ensue from (unjust) human agency, while LE is concerned with brute luck, which encompasses (others') human agency as well as natural events. If, for instance you got into Harvard because someone else's application accidentally got lost in the mail, this would not count as an injustice according to BPP, while according to LE, there wouldn't be much of a difference between this case and the original Harvard case.

Similarly, in the Polychrestos case, if the underground water system was upset by a minor earthquake (and D still hanged herself), BPP would remain silent, while LE would treat it the same way as the original case. BPP then, is concerned solely with injustice resulting from (unjust) human agency, and not at all with anything which is not an injustice (on this 
understanding), for instance earthquakes and other forms of bad brute luck which do not involve (unjust) agency. ${ }^{15}$

Second, BPP, but not LE, is only concerned with differential impacts of the same injustice. LE is preoccupied with just equality as such. On this view, whether or not the differential impact results from the same instance of injustice (or the same event), is completely irrelevant. If someone is bribed into Harvard, and someone else is denied admission due to a different, unrelated bribe, and there would have been room for both applicants, LE would require compensation (controlled for the welfare and responsibility levels of the agents). BPP, on the other hand, would not, since it is only concerned with the differential impact of the same injustice.

Note that this may call into question BPP's relevance in large-scale cases such as climate change and colonialism. It might be hard to argue that our forbear's emissions, for instance, constitute one instance of injustice. If so, adherents to BPP might consider Simon Caney's generalized version of BPP, according to which all innocent beneficiaries may gain duties to compensate any victims of injustice. ${ }^{16}$ In most discussions of BPP, however, the victim's and beneficiary's connection to the same injustice is crucial.

Third, BPP does not pay attention to the involved agent's welfare levels, apart from how that level is affected by a particular injustice. LE, on the other hand, is highly sensitive to these levels insofar as they display unjust inequalities. ${ }^{17}$ Imagine that for some very mysterious reason it turns out that GHG emissions in general have benefited the global poor, and harmed (an innocent portion of the) global rich, such that, in the absence of GHG emissions, the poor would have been even poorer, and the rich even richer. In that case, BPP (unless straddled with provisos) would imply that the global poor should compensate the (innocent portion of the) global rich. While this specific scenario seems unlikely, it is not at all unlikely that sometimes the beneficiary of injustice will be worse off than the victim of 
injustice. According to LE, on the other hand, the global poor should compensate only in the (also unlikely) event that they are, after having benefited, better off, controlled for responsibility, than the global rich. BPP is a principle aimed at cancelling out the effects of specific instances of injustice, rather than (undeserved) differences in welfare (or resources).

Fourth, LE, but not BPP is sensitive to other agents' welfare levels. According to LE, if the person who was wrongly admitted to Harvard, and the person who was wrongly denied admission, and all others, were after the bribe justly equally well off, no compensation would be called for. For LE to yield the same conclusion as BPP, the background conditions must be characterized by just equality. This, of course, is a simplification. There could be background conditions marked by unjust inequality such that distribution from the beneficiary to the victim would still be better all in all, than any other possible distribution. In the following I ignore such complexities. BPP, on the other hand, is insensitive to the welfare levels of other agents. It simply does not matter if others are worse off than, equally well off as, or better off than the beneficiary or the victim of injustice.

To sum up, according to LE, but not BPP, a) it does not matter whether or not the differential impact results from injustice or bad brute luck, b) it does not matter whether or not the differential impact results from the same instance of injustice (or bad brute luck), c) it does matter how well off the victim and the beneficiary are (for reasons outside their control) after the injustice has occurred, and d) it does matter how others fare (for reasons outside their control).

There are other differences as well. For one thing, LE is a more general principle than BPP. In addition, LE is a principle of distributive justice, while BPP is most reasonably seen as a principle of corrective justice. ${ }^{18}$ While these differences are noteworthy, I do not think they pertain to the relative plausibility of the principles. Perhaps the differences in generality and aim mean that LE and BPP are compatible, rather than competing. I do not have the space to 
pursue that question here, but I do think that a) they are in principle compatible, but that b) it is hard to find a plausible rationale for accepting such a combined view.

\subsection{Comparing Four Cases}

Consider four scenarios, based on the above distinctions, in which the two principles diverge:

1. A and B are differentially affected by a natural phenomenon (they were before the event justly equally well off).

2. A is harmed by an injustice and B benefits from a distinct injustice. The perpetrators of both injustices flee. A and B were before the unjust acts justly equally well off.

3. A and B are differentially affected by the same injustice. The perpetrator of the injustice flees. They were prior to the unjust act not justly equally well off (in the LE sense), but after the injustice, they are.

4. A and B are differentially affected by the same injustice. The perpetrator of the injustice flees. They were prior to the unjust act justly equally well off (in the LE sense), but others are (after the unjust act) either worse off than the victim, or better off than the beneficiary, for reasons that are both outside their control, and unrelated to the injustice in question. ${ }^{19}$

LE requires compensation from the beneficiary to the victim in cases 1 and 2, but not 3 and 4, while BPP requires compensation in 3 and 4, but not 1 and 2. (Hybrid principles are possible. Such views could for instance require compensation in 1, 2, and 3, or 2, 3, and 4.) In the following I will examine the plausibility of the answers LE and BPP give in the four cases.

Case 1: As noted, LE is triggered by any kinds of unchosen disadvantage (including random natural events), while BPP only applies to cases in which the unchosen disadvantage 
comes about through someone's (unjust) agency. In most versions at least, BPP does not require that Peter compensate Mary if Mary is harmed by the whirlwind which benefited Peter (It wrecked Mary's business, and uncovered a goldmine in Peter's garden). The idea, according to some defenders of BPP, is that there is something particularly bad about injustice, which makes it the case that it should be cancelled out. ${ }^{20}$ Differential brute luck is a different story altogether, and does not raise the same concerns. Of course, BPP can be combined with other principles which address deprivation not caused by unjust agency. However, for the BPP to make sense, such deprivation must surely be less morally offensive than deprivation that ensues from unjust agency. If not, deprivation that does not result from agency should also be encompassed by the principle. ${ }^{21}$

Are differential impacts of injustice worse than differential impacts of bad brute luck? In one sense, yes. Bad brute luck is unfortunate, but injustice is wrong. It is arguably worse that someone bribes their way into Harvard, than if someone gets in through an administrative mishap. It does not follow, however, that victims of bad brute luck have any less claim for compensation than victims of injustice. Consider the following scenario:

A and B are differentially affected by an injustice, the perpetrator of which flees (they were before justly equally well off). Subsequently, they are differentially affected (reversely) by a natural phenomenon (they are again equally well off).

According to LE (distributive) justice now reigns between A and B. According to BPP, however, the agent (A, say) who benefited from the injustice now owes B compensation. It seems that BPP's implication in this scenario is quite implausible.

Case 2: Here too, LE would demand compensation, whereas BPP would not. This raises the question of whether or not there is something special about being harmed and benefited by the very same injustice, as opposed to being harmed and benefited by distinct injustices. In 
my view, it is hard to see that being downstream causally related to the same injustice makes a difference. Imagine that $\mathrm{A}$ was bribed into Harvard at the expense of $\mathrm{B}$, and that $\mathrm{C}$ was bribed into Harvard at the expense of D. As a result, A and C have benefited substantially, and B and D have been substantially harmed. When the truth is finally uncovered, however, B and $\mathrm{C}$ are both dead. According to BPP, A does not owe D compensation, because A and D have not been harmed and benefited by the same injustice. Had B been alive, A would have owed her compensation. This seems unreasonable. Even if we leave open the question of whether A owes B (and C owes D) compensation, it is hard to justify the asymmetry between the cases ( $\mathrm{A}$ and $\mathrm{B}$ versus $\mathrm{A}$ and $\mathrm{D})$, because that asymmetry can only be explained with reference to a causal connection over which neither agent has any control whatsoever. ${ }^{22}$

One could argue, here as elsewhere, that BPP could surely be combined with further principles, in such a way that D could be compensated for other reasons. It could make sense to hold that a) the perpetrator should compensate, but if the perpetrator is unavailable, b) the beneficiary should compensate, and if the beneficiary is unavailable, c) victims of injustice should be compensated in light of some further principle of corrective or distributive justice. Most likely, such a principle would hold that others share the cost of the compensation (perhaps in proportion to their ability). The case I have outlined would only serve to undermine versions of the BPP which omits c).

However, suppose we include c). Would that be enough to think BPP is plausible in this case? Such an inclusion would surely reduce the intuitive force of case 2 . But other problems may arise. If we accept (as we should) that victims of injustice should be compensated even if the beneficiary is unavailable, it is unclear why the beneficiary, when available, should take on the total of the burden. It is easy to accept that perpetrators should compensate - they have committed an injustice - but harder to see why beneficiaries should do so - they are innocent. In the case described, (assuming both B and D are still alive) the beneficiary (A) would face a 
much greater cost than the other agents who are asked to (collectively) compensate. Why should this be the case? One could say that the beneficiary is better off than others, as she has benefitted from injustice, but that is a) not always the case, and b) not the reason invoked by BPP-defenders. If we allow welfare considerations into the picture (which I think we should), we do not really need BPP. To be sure, those who benefit from injustice might be well off, and if so, they should chip in for that reason. But then we are fast approaching more general distributive principles, and the case for a distinct BPP weakens accordingly.

Case 3: Here, BPP, but not LE, would require compensation. If $\mathrm{A}$ is bribed into Harvard at B's expense, A owes B compensation, in virtue of having benefited from injustice, even if B is now (for brute luck reasons) as well off as $\mathrm{A} .{ }^{23}$ For egalitarians in general, and LEproponents in particular, this seems to be the wrong answer. It would also seem to be the wrong answer even to those with more modest forms of equality aversion, especially if we sharpen the case by assuming that $\mathrm{B}$ is substantially better off than $\mathrm{A}$, even if she was deprived of a Harvard education, and even if this seen in isolation, made her worse off (before unrelated good brute luck made her very well off).

One could argue that BPP does not apply to these kinds of scenarios. For instance, BPP could be combined with an absolute threshold, such that if the beneficiary ends up badly off in absolute terms, the duties generated by BPP fade away. Alternatively, one could hold that the duty to compensate because one has benefited from an injustice that has harmed another is contingent on the beneficiary's being better off than the victim (call this BPP*). Assume that $\mathrm{A}$ is benefited and $\mathrm{B}$ is harmed by an injustice, and $\mathrm{C}$ is an innocent third party. The distribution after the injustice is like this:
A: $14, B: 10, C: 30$ 
Thus, BPP* would call for the following adjustment.

A: $10, B: 14, C: 30$

(Or, depending on how the equality requirement is to be interpreted, BPP* would mandate

A: $12, \mathrm{~B}: 12, \mathrm{C}: 30)$

What is unclear here, of course, is why exactly A should redistribute four (or two) units of welfare to $\mathrm{B}$, when $\mathrm{C}$ is, in comparison, so much better off. I am not pushing a whole-sale egalitarian agenda here. The point is simply to ask why BPP* seeks equality (or at least less inequality stemming from being harmed or benefited by the same unjust action) between $\mathrm{A}$ and $\mathrm{B}$, but not between these two and $\mathrm{C}$. Why should equality matter only when two agents are differentially affected by the same unjust action and the beneficiary ended up better off? Or rather, why would anyone think that even smallish inequalities are morally important in BPP* scenarios, while even large inequalities are irrelevant when they obtain between agents who have not been affected by the same action? Unless BPP is just to collapse into equality, this distinction must be upheld, in one form or the other.

Case 4: Here, LE would again not demand compensation from the beneficiary to the victim (though it would require some form of distribution), whereas BPP would. According to Knight, this challenge to BPP has two aspects. First, there could be a bystander, unrelated to the injustice in question, who is, through brute luck, as well off as the beneficiary (Bystander case). Secondly there could be an unfortunate person, also unrelated to the injustice in question, who is, through brute luck, as badly off as the victim (Unfortunate case). ${ }^{24}$ 
As Knight notes, BPP does not imply that the bystander should compensate the victim (in the Bystander case), or that the unfortunate person can claim assistance from the beneficiary (in the Unfortunate case). Rather, BPP is concerned solely with the supposedly morally salient connection between the beneficiary and the victim. ${ }^{25}$

The cases can be sharpened. Suppose, in the Bystander case, that many are much better off than the beneficiary, and that in the Unfortunate case, many are much worse off than the victim. It seems unreasonable to insist that the balance must be reestablished between the beneficiary and the victim, while the balance between these two and all others unrelated to the particular injustice, is of no consequence. (This is related to the above discussion of BPP*).

There are, however, cases similar to the Bystander case, but with a bit more context that are thought to support BPP. In these cases, a victim of injustice must either be compensated by the beneficiary (of that injustice) or by some other agent who has benefited equally from good brute luck. There is no way, we can assume, for the beneficiary and the person with good brute luck to share the burden. Assume, in the Polychrestos-case, that there is a fifth person on the island, E, who is as laid-back as B, C, and D, and who is unaffected by D's water-manipulations. E, however, has benefited from unexpected and (very) local rainfalls. She can therefore, like B, harvest 400 kilos (rather than 200 kilos) of polychrestos. Thus, both B and E have a surplus of 200 kilos for reasons outside their control. Suppose further that E and $\mathrm{B}$ for some reason are simply unable to share the burden. If $\mathrm{C}$ is to survive, one of them has to pay in full. ${ }^{26} \mathrm{BPP}$-defenders argue that in this case, it seems that B should pay, rather than E. In my view, however, E and B are symmetrically situated with regards to C. ${ }^{27}$ They have both gained for reasons outside their control. It would be better to toss a fair coin, than for B to pay just because she is an innocent beneficiary of injustice.

Notice, however, that to the extent that some people feel that there are still reasons to drop the coin toss, and just let B pay up, this could be because there is an underlying sense that D, 
when diverting the underground river, in some sense stole from $\mathrm{C}$, because $\mathrm{C}$ owned her part of the water resources. This sounds reasonable, but if so, the Polychrestos case should be amended. The case is intended to support BPP, and not (merely) support the idea that one should return stolen goods (or the immediate fruits of stolen goods). Our intuitions about private property and theft, moreover, are so strong and inculcated, that BPP should be assessed in isolation from these features.

Consider the following variation of the case. When D diverts the water away from (her own and) C's plot, the water is not redirected towards B. Rather it flows out into the sea. However, as C's (and D's) plants shrivel and die, B's plot (as a result) receives more sunlight, which causes her harvest to double. Meanwhile, E's land is drizzled by the local rain, A is still hardworking and unaffected by these events, and D hangs herself. In this case, the extra sunlight does not in any meaningful sense belong to C. B, however, has still benefited from injustice, and E has benefited from good brute luck. Should B pay, rather than E, if they cannot share the cost? I think not. Suppose E told B to pay because B, but not E was in fact a beneficiary of injustice. If so, B could reply that it is just E's good luck that he benefited from brute luck rather than injustice. It does not seem right that such a superficial difference should tip the balance. Here too, of course, the case can be sharpened. We could imagine that the local rainfall caused E's crop to triple rather than double. This would cast further doubts on BPP's implications.

BPP might again be amended to accommodate the concern raised by Knight's two cases. However, any such accommodation, will blur the distinction between BPP and LE, and threaten to undermine BPP as a distinct principle. More generally, in all the cases discussed, BPP might be amended, in order to yield more palatable implications. Any such amendment, however, pushes BPP in the direction of LE, or towards some other general principle of distribution. This gives us reason to doubt that that BPP is viable as a distinct principle. ${ }^{28}$ 
One might be tempted to question the very purpose of comparing these two principles, on the grounds that they attempt to answer different questions. As noted, BPP is most plausibly seen as a principle of corrective justice which aims to make right some specific instances of injustice. LE on the other hand, is a principle of distributive justice, providing a more general view of how welfare (or resources) should be allocated. ${ }^{29}$ Thus, comparing them is like comparing apples and oranges. In my view, however, BPP and LE are indeed comparable. LE, on most interpretations, implies a view of corrective justice. If it is bad that someone is worse off than others through no fault or choice of her own, then it seems natural that transfers from someone who is better off than others through no fault or choice of her own to someone who is worse off than others through no fault or choice of her own, makes the situation better. Further, it seems plausible that LE is applicable to the cases discussed above, which from the perspective of BPP are indeed cases of corrective justice. Thus, since both principles address such cases, I assume that they are relevantly comparable.

\section{Assessing Defenses of BPP}

Even if intuitive responses to hypothetical cases are clearly relevant, we should also consider more general justifications for BPP. In this section I will first examine Butt's claim that rejecting BPP is incompatible with a true aversion to injustice. ${ }^{30}$ On this view, it is morally important that those who benefit, benefit from injustice. Their benefit is tainted, and there is an imbalance that stands in need of correction. In addition I discuss (more briefly) the idea that the beneficiary should compensate the victim because of the causal connection between the two of them. Lastly, I consider the suggestion that the beneficiary should compensate because even if she is innocent with regards to the justice, she is not necessarily innocent with regards to accepting and retaining the benefits of injustice. 


\subsection{Is it Conceptually Flawed to Denounce Injustice while Keeping the Benefits thereof?}

According to Butt:

The individual's duty not to benefit from another's suffering when that suffering is a result of injustice stems from one's condemnation of the unjust act itself...[T]aking our nature as moral agents seriously requires ... that we hold a genuine aversion to injustice and its lasting effects. We make a conceptual error if we condemn a given action as unjust, but are not willing to reverse or mitigate its effects on the grounds that it has benefited us. The refusal undermines the condemnation. The belief that certain acts are wrong and should not be performed on account of their harmful consequences commits one to endorse the application of rectificatory justice to seek to undo the effects of injustice...Losses which others suffer as a result of the unjust actions of other persons ...create distortions in the scheme of fair distribution. If no one else is willing or able to make up these losses, then the duty falls to those who are benefiting from the distortions... ${ }^{31}$

While this passage constitutes an interesting explication of the rationale behind BPP, I do not think it succeeds in justifying that principle in particular. In order to simplify matters, I will try to distill four distinct claims that Butt seems to make.

1. We have a duty not to benefit from injustice to others.

2. We make a conceptual error if we condemn an injustice but are not willing to divest ourselves of whatever we have benefited from (that) injustice.

3. Victims of injustice should be compensated.

4. Beneficiaries of injustice should compensate the victims of injustice if no one else is willing or able.

First, there seems to be some tension between 1 and 4. 1, moreover, seems too strong to be compatible with the general drift of Butt's defense of BPP. He says elsewhere, in line with 4, 
that being a beneficiary of justice may give rise to compensatory duties. ${ }^{32}$ Thus, in the following, I ignore $1 .^{33}$

4 seems ambiguous. In one sense, it is too weak to ground BPP. In most circumstances there are some agents that are either willing or able to compensate victims. In the Polychrestos case, A, who is hardworking and unaffected by D's scam, is clearly able to compensate, yet Butt does not let B off the hook for that reason. ${ }^{34}$ In general, the relation between BPP and other possible grounds for compensatory duties should be clarified. ${ }^{35}$ In another sense, however, 4 is too strong, for reasons given above. (It ignores, for instance, the beneficiary's welfare level). All in all, it is hard to assess this claim without further specification.

Claim 3 seems acceptable within reasonable limits. Most people would accept that victims in general should be compensated. But this claim is not very specific, and is compatible with a range of different principles that do not single out beneficiaries in particular. (Again, Butt mentions other grounds on which compensatory duties may be based).

I take it that claim 2 is the most important part of the defense. This claim holds that it is conceptually flawed to denounce injustice while not being willing to give up what one has benefitted thereof. The claim seems compatible with 1, however, which I have chosen to ignore (based on my interpretation of Butt's position). It seems better to understand it in line with a more victim-based understanding of BPP, and add the condition suggested by 4 :

If $\mathrm{A}$ benefits from an unjust act that harms $\mathrm{B}, \mathrm{A}$ makes a conceptual mistake if she i) denounces the injustice towards B, and yet ii) refuses to compensate B, even if no other agents have compensatory duties towards B (for instance the perpetrator).

In my view, this claim is not, in general, true. As noted, I think that we have good reason to think that victims of injustice often have claims for compensation, but I do not think that it is conceptually true that beneficiaries ought to compensate. First, as noted, there are cases in 
which the beneficiary is worse off than the victim. To drive the point home, suppose that the beneficiary is dependent for her survival on what she has benefited from injustice, while the victim lacks for nothing. It seems to me that the beneficiary may well denounce the injustice, while still refusing to compensate, without committing any conceptual mistakes. Second, while claim 2 might be intuitively plausible in cases where the benefits are material and easily transferable (being in possession of stolen goods), it seems less plausible in other situations. ${ }^{36}$ Consider a revised version of Goodin and Barry's Harvard case.

A's father bribed her into Harvard. As a result, B was harmed. However, because A was admitted to Harvard, she declined an offer from a less prestigious school. As a result $\mathrm{C}$ was admitted to the less prestigious school, which, though less prestigious than Harvard, is far more prestigious than any other school $\mathrm{C}$ had offers from. Many years later, the truth is uncovered. A is by then dead.

$\mathrm{C}$ is clearly a beneficiary of injustice, in much the same way as A (and D who was admitted to the school that $\mathrm{C}$ declined, and so on). Is really $\mathrm{C}$, of all people, morally responsible for compensating B's loss? Imagine you are C. Imagine that you are retired and an alumnus of a good university. Your life has gone well, partly as a result of a good education. Then someone appears at your doorstep claiming substantial compensation because some other person you have never heard of was bribed into Harvard back in the day. Would you really think that you had a moral duty to pay up? Would you, moreover, make a conceptual error if you refused? To me the claim sounds preposterous. Not because B does not have a valid claim to compensation, but because $\mathrm{C}$ does not appear to have a special moral duty to bear the (the total of that particular) cost. Rather, the cost should be shared among able bystanders in light of some plausible principle of burden-sharing.

One might wonder why the Harvard case, which is intended to support the BPP, becomes so much less persuasive (in my view at least) when it is altered like this. One reason might be 
that in the original case, the person who is bribed into Harvard is the intended beneficiary of her father's crime. $\mathrm{C}$ on the other hand is merely a random beneficiary. This feature, however, which Goodin and Barry (rightly) dismiss as morally irrelevant, is not something on which the BPP generally relies. ${ }^{37}$ The original case should be as persuasive without it. We could, for instance, imagine that some malicious person bribed a Harvard official in order to secure that his enemy was denied admission, and as a consequence the next applicant in line, with no relation to the perpetrator, was admitted instead. This is presumably a case which most BPP proponents would want their principle to cover.

Another reason why the revised Harvard case seems less persuasive, might be that $\mathrm{C}$, who was admitted to the school whose offer A declined, is causally one step removed from the original harm. To be sure, defenders of the BPP must probably invoke some limiting principle, because the consequences of most acts, just or unjust, will keep flowing throughout history. In the case at hand, however, the causal chain is really not that long. Keeping in mind that the BPP is often invoked in cases of historic injustice, it would be hard to maintain that only the most immediate consequences should matter from the point of view of justice. Suppose A is harmed immensely by an injustice that benefits B immensely. Shortly after, both $\mathrm{A}$ and $\mathrm{B}$ dies, and transfer their respective losses and benefits to their children. Again, this seems to be a sort of case most BPP defenders would want their principle to cover.

I take it that these considerations are sufficient to show that it is not conceptually flawed to denounce an instance of injustice without being willing to give up what one has benefited thereof. One could object here that while it may not be, strictly speaking, conceptually flawed to refuse to give up what one has benefited from injustice, it might be wrong in some other way. This is in one sense a reasonable objection, but it seems unclear to me what this wrongness consists in. Further, the revised Harvard-case above does, in my view, not merely refute the view that it is conceptually flawed not to give up what one has benefited from 
injustice. Rather it questions whether there is anything generally wrong in refusing to give up such benefits (which, again, is not to say that beneficiaries should not, along with others, contribute to compensating victims of injustice).

\subsection{The Moral (in)significance of Causality}

Some BPP-defenders might find relevant the fact that the beneficiary is causally connected to the victim. Causal connection seems clearly relevant in some cases. If Alice harms Betty, most would agree that Alice should compensate. There is a difference, however, between causing and being caused. The beneficiary of injustice does not cause anything (as far as the injustice is concerned). Rather she is being affected by someone else's (the perpetrator's) action. To me it seems that what makes causing harm relevant is the fact that the causer (often) controls the harm. ${ }^{38}$ And tellingly, if the causer does not control the harm, she will often be excused (for instance if she is manipulated or forced to inflict the harm).

Suppose Alice benefits from an injustice towards Betty. The benefit is not material, and not such that it is reasonable to say that Alice now possesses something of Betty's. Alice gains 10 units, whereas Betty loses 10. At the same time, Clare is harmed through sheer bad brute luck. Both Betty and Clare are now quite badly off. Suppose that there are no one else who can compensate either Betty or Clare. Thus, Alice have 10 units to spare, and 5 units would mean a lot, and equally much to Betty and Clare. Should Alice prioritize Betty? If causal connection is morally salient, it seems that she should. In my view, however, she should not. It is better if she divides the 10 units equally between the Betty and Clare. It would not be easy for Alice to explain to Clare that she should have less than Betty just because Betty and Alice happened to be involuntarily affected by the same causal chain. Since neither of the three instigated or influenced that chain, it should play no moral role. If so, the causal connection that exists between Alice and Betty is insignificant. ${ }^{39}$ Intuitions will surely differ here, and the case is not 
a knock-down argument against those who think causal connection matters. I hope however that these remarks go some way towards supporting my conviction that causal connection, at least downstream causal connection, is morally insignificant.

\subsection{Are the Beneficiaries Really Innocent?}

One could argue that there is a sense in which the beneficiary is not completely innocent, contrary to the assumption made so far. Even though the beneficiary is innocent with regards to the injustice as such, she is not innocent with regards to accepting the benefit. Whether or not she can be said to accept the benefit will depend on her knowledge. In the revised Harvard case, $\mathrm{C}$ does not accept the benefits of injustice simply by accepting the offer from the less prestigious school. She only (relevantly) accepts such a benefit after she is made aware of the injustice that led to the offer. So the question is, does $\mathrm{C}$ lose her innocence (in a relevant way) the moment she learns the truth? If so, we might argue that she should indeed bear a special responsibility to compensate $\mathrm{B}$ after all.

In reply, it is worth considering again the revised Harvard case. I have suggested that it seems wrong to say that $\mathrm{C}$ should bear a special responsibility for compensating $\mathrm{B}$. This result is based on an assessment of the case. To say that $\mathrm{C}$, after she learns the truth, is no longer innocent (with regards to accepting the benefit), is presumably to say, to the contrary, that $\mathrm{C}$ should pay B. But it is not clear that merely declaring C 'not innocent' in this particular sense does much independent work here. Whether or not $\mathrm{C}$ is (relevantly) innocent depends on the prior question of whether or not her benefit is wrongly accepted and retained, and not the other way around. In other words, to say that $\mathrm{C}$ should pay because she is not innocent with regards to accepting the benefit is to presuppose that (knowingly) benefiting from injustice gives rise to special duties of compensation. But this cannot be presupposed in a context in which we try to figure out whether or not it is correct. ${ }^{40}$ 


\section{Concluding Remarks}

BPP and LE tend to yield overlapping implications in isolated cases, despite many differences in structure and scope. In this paper, I have tried to canvass the most salient differences between the principles and assess their relative plausibility. This assessment led to the conclusion the BPP is clearly less plausible than BPP. Further, I have argued that some promising defenses of BPP are ultimately unsuccessful.

For very useful comments on earlier versions of this paper, I am grateful to Kim Angell, Christian Barry, Ludvig Beckmann, Bengt Brülde, Daniel Butt, Lars Christie, Alexandra Couto, Jakob Elster, Eli Feiring, Henrik Friberg-Fernros, Göran Duus-Otterström, Bashshar Haydar, Clare Heyward, Fredrik Dybfest Hjorthen, Andreas H. Hvidsten, Cathrine Holst, Carl Knight, Kasper Lippert-Rasmussen, Raino Malnes, Grethe Netland, Michael Otsuka, Gerhard Øverland, and two anonymous reviewers for this journal. Work on this article has been supported by the Norwegian Research Council (Grant number: 222541).

\footnotetext{
${ }^{1}$ Carl Knight, "Benefiting from Injustice and Brute Luck," Social Theory and Practice 39 (2013): 581-598. The overlap between LE and BPP is also noted in Robert Huseby, "Should the Beneficiaries Pay?" Politics, Philosophy \& Economics 14 (2015): 209-225. See also Daniel Butt, Rectifying international injustice principles of compensation and restitution between nations. Oxford: Oxford University Press, 2009), 98-99.

${ }^{2}$ Simon Caney, "Cosmopolitan Justice, Responsibility and Global Climate Change," Leiden Journal of International Law 18 (2005): 747-75; Simon Caney, "Environmental Degradation, Reparations and the Moral Significance of History," Journal of Social Philosophy 37 (2006): 464-82; Simon Caney, “Climate Change and the Duties of the Advantaged," Critical Review of International Social and Political Philosophy 13 (2010): 20328; Edward Page, "Give it Up for Climate Change: A Defense of the Beneficiary Pays Principle," International Theory 4 (2012): 300-330.

${ }^{3}$ Butt, Rectifying international injustice - principles of compensation and restitution between nations.
} 
${ }^{4}$ As noted, there are versions of BPP that include (mere) harmful acts, and harmful events. Here, however, I consider BPP in a version that focuses specifically on unjust acts that cause harm.

5 This statement of BPP is taken, with small modifications, from Huseby, "Should the Beneficiaries Pay?" 210.

${ }^{6}$ Daniel Butt, "On Benefiting from Injustice," Canadian Journal of Philosophy 37 (2007): 129-52; Butt, Rectifying international injustice - principles of compensation and restitution between nations; Daniel Butt, “"A Doctrine Quite New and Altogether Untenable': Defending the Beneficiary Pays Principle," Journal of Applied Philosophy 31 (2014): 336-348; Robert Goodin and Christian Barry, "Benefiting from the Wrongdoing of Others." Journal of Applied Philosophy 31 (2014): 363-376; Axel Gosseries, "Historical Emissions and Freeriding," Ethical Perspectives 11 (2004): 30-60; Bashshar Haydar and Gerhard Øverland, “The Normative Implications of Benefiting from Injustice," Journal of Applied Philosophy 31 (2014): 349-362; Page, “Give it Up for Climate Change: A Defense of the Beneficiary Pays Principle;" Avia Pasternak, "Voluntary Benefits from Wrongdoing,” Journal of Applied Philosophy 31 (2014): 377-391.

${ }^{7}$ Knight, "Benefiting from Injustice and Brute Luck;" Huseby, "Should the Beneficiaries Pay?"; Leif Wenar, “Reparations for the Future,” Journal of Social Philosophy 37 (2006): 396-405.

${ }^{8}$ Larry Temkin, Inequality (Oxford: Oxford University Press, 1993), 13.

${ }^{9}$ G. A. Cohen, On the Currency of Egalitarian Justice, and other Essays in Political Philosophy, ed. Michael Otsuka (Princeton and Oxford: Oxford University Press, 2011), 119.

${ }^{10}$ Richard Arneson, "Equality and Equal Opportunity for Welfare," Philosophical Studies 56 (1989): 77-93, 85.

${ }^{11}$ Kasper Lippert-Rasmussen, “Debate: Arneson on Equality of Opportunity for Welfare,” The Journal of Political Philosophy 7 (1999): 478-487, 479. For the view that equalities do not need to be justified, see Shlomi Segall, "Why Egalitarians Should Not Care About Equality," Ethical Theory and Moral Practice 15 (2012): 507519. Note further that the quotes in the text refer to a version of luck egalitarianism that is preoccupied with choice and responsibility. There are also several other versions, such as moral and prudential desert luck egalitarianism. These other versions, however, fall beyond the scope of the present paper. For an overview of the variants of luck egalitarianism, see Kasper Lippert Rasmussen, "Justice and Luck: Revised Edition," in Stanford Encyclopedia of Philosophy (2014) (http://plato.stanford.edu/entries/justice-bad-luck/).

${ }^{12}$ See for instance Goodin and Barry, "Benefiting from the Wrongdoing of Others." Notice, however, that the choice of currency will not affect the conclusions of this paper to any great extent.

${ }^{13}$ Butt, “On Benefiting from Injustice,” 132. 
${ }^{14}$ Goodin and Barry, "Benefiting from the Wrongdoing of Others," 365. See Gosseries "Historical Emissions and Free-riding;" Butt “'A Doctrine Quite New and Altogether Untenable': Defending the Beneficiary Pays Principle;" and Haydar and Øverland “The Normative Implications of Benefiting from Injustice," for further cases aimed at supporting the BPP.

${ }^{15}$ Again, BPP can be defined in a different ways. See note 4 above.

${ }^{16}$ Caney, "Climate Change and the Duties of the Advantaged."

${ }^{17}$ As noted, I assume here a welfarist interpretation of the view.

${ }^{18}$ See Butt, Rectifying international injustice - principles of compensation and restitution between nations, ch. 2.

I briefly discuss the relevance of the distinction between distributive and corrective justice below.

${ }^{19}$ Versions of these scenarios have been discussed by Knight, "Benefiting from Injustice and Brute Luck;"

Wenar, "Reparations for the Future," and Huseby, "Should the Beneficiaries Pay?" Wenar notes in particular scenario 3. Knight focuses on 1 and 4, while Huseby is mainly concerned with 2 and 4. None of these papers track systematically the differences between LE and BPP, and only Knight is preoccupied particularly with the relative assessment of LE and BPP.

${ }^{20}$ Butt, Rectifying international injustice - principles of compensation and restitution between nations, 128.

${ }^{21}$ A BPP encompassing differential brute luck (in relation to some specific event) would of course avoid the problems raised by case 1 . On the other hand, it would be difficult to justify that differential brute luck matters morally only when brought on by the same event.

${ }^{22}$ Huseby, "Should the Beneficiaries Pay?" I return to the potential significance of causality in 4.2 below.

${ }^{23}$ Wenar, "Reparations for the Future."

${ }^{24}$ Knight, "Benefiting from Injustice and Brute Luck," 587.

${ }^{25}$ Butt, Rectifying international injustice - principles of compensation and restitution between nations, 133 . See also Knight, "Benefiting from Injustice and Brute Luck," 587-588.

${ }^{26}$ I am grateful to both Henrik Friberg-Fernros and Robert Kirby for suggesting versions of this case.

${ }^{27}$ Some versions of LE might also treat the two cases differently. Asymmetrical versions hold that only bad brute luck should be equalized and not (necessarily) good brute luck. In this paper I assume the (more common) symmetrical version according to which all forms of brute luck should be equalized).

${ }^{28}$ It also, incidentally, gives us reason to doubt that hybrid versions are plausible (though some of them might well be more plausible than the standard BPP). 
${ }^{29}$ See Butt, Rectifying international injustice - principles of compensation and restitution between nations, ch. 2 , for more on the distinction between corrective and distributive justice.

${ }^{30}$ Other defenses are available too. Knight discusses unjust enrichment and free-rider issues (Knight, "Benefiting from Injustice and Brute Luck"). I think however, that BPP is different from both unjust enrichment and freerider problems, something with which Knight seem to agree.

${ }^{31}$ Butt, Rectifying international injustice - principles of compensation and restitution between nations, 127-128.

${ }^{32}$ Butt, Rectifying international injustice - principles of compensation and restitution between nations, 120.

${ }^{33}$ This is not to say that a duty not to benefit from injustice is indefensible. I think however, that such a duty is distinct from the BPP as discussed here, since a duty not to benefit seemingly exceeds our potential duty to compensate. The reason is that we could have this duty even if the victim is no longer around. If so we should presumably disgorge our benefits.

${ }^{34}$ See Knight, "Benefiting from Injustice and Brute Luck," 584.

${ }^{35}$ In addition to ability, Butt (drawing on Miller) mentions causal responsibility, moral responsibility and communal obligations (See Butt, Rectifying international injustice - principles of compensation and restitution between nations, 118-119. See also David Miller, "Distributing Responsibilities," Journal of Political Philosophy 9 (2001): 453-471.

${ }^{36}$ See Knight, "Benefiting from Injustice and Brute Luck,”592, Bashshar Haydar, "Special Responsibility and the Appeal to Cost," Journal of Political Philosophy 17 (2009): 129-145, 142.

${ }^{37}$ According to Goodin and Barry, "Benefiting from the Wrongdoing of Others," 371: "The wrong-doer's guilty mind does not make you (the unwitting but intended beneficiary of his wrongdoing) morally tainted in any way. That is just not the way mens rea works. Intentions just do not transmit across benefits, like that.” See however Haydar and Øverland, "The Normative Implications of Benefiting from Injustice," for a defense of the moral relevance of being the intended beneficiary of harm. See also Butt Rectifying international injustice - principles of compensation and restitution between nations, 129-130.

${ }^{38}$ See Huseby, "Should the Beneficiaries Pay?" 218.

${ }^{39}$ For a related discussion, See Huseby, "Should the Beneficiaries Pay?"

${ }^{40}$ There could of course be cases in which accepting benefits of injustice may be wrong. According to Barry and Wiens, accepting and retaining benefits of injustice is wrong when doing so sustains wrongful harm. But many cases of benefiting from injustice are not like this. (See Christian Barry and David Wiens, "Benefiting from 
Wrongdoing and Sustaining Wrongful Harm," Journal of Moral Philosophy (forthcoming) 10.1163/174552434681052. 